\title{
Alterações moleculares no desenvolvimento do câncer de próstata
}

\author{
Molecular changes in the development of prostate cancer \\ Alteraciones moleculares en el desarrollo del cáncer de próstata
}

Recebido: 28/11/2021 | Revisado: 06/12/2021 | Aceito: 10/12/2021 | Publicado: 20/12/2021

\author{
Açucena de Oliveira Borges \\ ORCID: https://orcid.org/0000-0003-1781-0870 \\ Faculdade Morgana Potrich, Brasil \\ E-mail: assucena-o-b-@hotmail.com \\ Juliana Paniago Souza \\ ORCID: https://orcid.org/0000-0001-5313-7922 \\ Faculdade Morgana Potrich, Brasil \\ E-mail: jupaniago@msn.com \\ Letícia Góes Pereira \\ ORCID: https://orcid.org/0000-0002-0331-190X \\ Faculdade Morgana Potrich, Brasil \\ E-mail: leticiagoes98@hotmail.com \\ Eriston Vieira Gomes \\ ORCID: https://orcid.org/0000-0002-5538-0106 \\ Faculdade Morgana Potrich, Brasil \\ E-mail: eristongomes@alumni.usp.br
}

\begin{abstract}
Resumo
Introdução: O câncer de próstata (CP) é o segundo mais diagnosticado na população masculina do mundo. Clinicamente, o CP é subdividido em câncer primário, câncer de próstata metastático resistente à castração e o câncer de próstata neuroendócrino. Objetivo: descrever as principais alterações moleculares necessárias para o desenvolvimento do câncer de próstata primário (CPa). Metodologia: trata-se de uma revisão descritiva da literatura. Foram utilizadas as bases de dados PUBMED, SCIELO, Science Direct e Google Acadêmico e Instituto Nacional de Câncer (INCA). Como critério de inclusão/exclusão, foram artigos compreendidos entre 2015 a 2021, disponíveis em português, inglês e espanhol. Resultados e discussão: as bases moleculares do $\mathrm{CP}$ apresentam várias alterações genômicas como mutações, alterações de número de cópias de DNA, rearranjos e fusões de genes. Para o câncer primário, as alterações genéticas mais prevalentes são alterações dos genes da família ETS tais como, fusões dos genes $E R G$ (os quais ocorrem em 50\% dos casos e mutações principalmente nos genes CHD1, SPOP e BRCA1 ou BRCA2). Já o câncer de próstata metastático resistente à castração, a alteração genética mais prevalente altera receptores de andrógeno e oncossupressores (e.g. PTEN e TP53). Conclusão: alterações em níveis genético e epigenético em genes específicos regulados por hormônios andrógenos, estão intimamente relacionados à patogênese do CP. Esses dados são de suma importância para a compreensão do mecanismo fisiopatológico desta condição, bem como oferecem a base para um tratamento mais específico.
\end{abstract}

Palavras-chave: Câncer de próstata; Alterações moleculares; ETS.

\begin{abstract}
Introduction: Prostate cancer (PC) is the second most diagnosed in the male population in the world. Clinically, $\mathrm{PC}$ is subdivided into primary cancer, castration-resistant metastatic prostate cancer, and neuroendocrine prostate cancer. Objective: to describe the main molecular changes necessary for the development of primary prostate cancer ( $\mathrm{PCa})$. Methodology: this is a descriptive literature review. The databases PUBMED, SCIELO, Science Direct and Academic Google and National Cancer Institute (INCA) were used. The inclusion/exclusion criteria were articles from 2015 to 2021, available in Portuguese, English and Spanish. Results and discussion: the molecular bases of PC present several genomic alterations such as mutations, alterations in the number of copies of DNA, rearrangements and gene fusions. For primary cancer, the most prevalent genetic alterations are alterations in the ETS family genes such as ERG gene fusions (which occur in 50\% of cases and mutations mainly in the CHD1, SPOP and BRCA1 or BRCA2 genes). In castration-resistant metastatic prostate cancer, the most prevalent genetic alteration alters androgen receptors and oncosuppressors (e.g. PTEN and TP53). Conclusion: alterations in genetic and epigenetic levels in specific genes regulated by androgen hormones are closely related to the pathogenesis of PC. These data are of paramount importance for understanding the pathophysiological mechanism of this condition, as well as providing the basis for a more specific treatment.
\end{abstract}

Keywords: Prostate cancer; Molecular alterations; Genes ETS. 


\section{Resumen}

Introducción: El cáncer de próstata $(\mathrm{CP})$ es el segundo más diagnosticado en la población masculina del mundo. Clínicamente, el CP se subdivide en cáncer primario, cáncer de próstata metastásico resistente a la castración y cáncer de próstata neuroendocrino. Objetivo: describir los principales cambios moleculares necesarios para el desarrollo del cáncer de próstata primario $(\mathrm{CaP})$. Metodología: se trata de una revisión descriptiva de la literatura. Se utilizaron las bases de datos PUBMED, SCIELO, Science Direct y Google Academic y National Cancer Institute (INCA). Los criterios de inclusión / exclusión fueron artículos de 2015 a 2021, disponibles en portugués, inglés y español. Resultados y discusión: las bases moleculares del PC presentan diversas alteraciones genómicas como mutaciones, alteraciones en el número de copias de ADN, reordenamientos y fusiones de genes. En el caso del cáncer primario, las alteraciones genéticas más prevalentes son las alteraciones en los genes de la familia ETS como las fusiones del gen $E R G$ (que ocurren en el 50\% de los casos y mutaciones principalmente en los genes CHD1, SPOP y BRCA1 o BRCA2). En el cáncer de próstata metastásico resistente a la castración, la alteración genética más prevalente altera los receptores de andrógenos y los oncosupresores (e.g. PTEN y TP53). Conclusión: las alteraciones en los niveles genéticos y epigenéticos en genes específicos regulados por hormonas andrógenas están estrechamente relacionadas con la patogenia del CP. Estos datos son de suma importancia para comprender el mecanismo fisiopatológico de esta afección, además de proporcionar la base para un tratamiento más específico.

Palabras clave: Cáncer de próstata; Alteraciones moleculares; Genes ETS.

\section{Introdução}

Câncer é uma palavra utilizada para denominar um conjunto de doenças de caráter maligno, caracterizadas pelo crescimento desorganizado das células. Estas células apresentam alterações morfológicas, estruturais e metabólicas, bem como uma taxa de divisão acelerada. Sobretudo, o câncer é uma condição patológica de natureza genética, ocorrendo a partir de alterações em regiões específicas do DNA da célula (INCA, 2020). Denomina-se carcinogênese o processo para a formação do câncer. Esse processo é composto por três estágios, iniciação, promoção e progressão. O estágio de iniciação é caracterizado pela alteração de alguns genes específicos, preparando as células para a próxima fase. Já no estágio de promoção, a célula modificada torna-se maligna em um período relativamente lento, mas para isso faz-se necessário um longo contato com o agente cancerígeno. Por fim, no estágio de progressão, ocorre uma proliferação desordenada, acumulando as células cancerosas que geram o tumor. Nesse estágio, o câncer já está presente e promove manifestações clínicas. Todas essas fases podem levar anos até que o tumor apareça e os primeiros sinais e sintomas se manifestem (INCA, 2017).

\subsection{Câncer de próstata}

A próstata faz parte do sistema reprodutor masculino, sendo uma glândula localizada anteriormente ao reto e abaixo da bexiga. Apresenta um peso aproximado de 20 gramas, tendo um formato que se assemelha a uma noz e possui função secretora. Dentre os diversos tipos de cânceres, o câncer de próstata é o segundo mais diagnosticado na população masculina no Brasil e no mundo (atrás apenas do câncer de pele não-melanoma) (Sarris et al., 2018; INCA, 2020). O que mais chama a atenção é o fato de a taxa de incidência estar em crescente aumento e ser maior nos países desenvolvidos em comparação aos países subdesenvolvidos. De acordo com INCA, no Brasil, a estimativa anual entre os anos 2020 e 2022 é de que ocorrerão cerca de65.840 novos casos de CP correspondendo a 29,2 \% de todas as neoplasias masculinas, exceto o câncer de pele não melanoma. O número de mortes no Brasil, no ano de 2019, último ano informado pelo Ministério da Saúde, foi de 15.983 casos. Em se tratando das regiões brasileiras, no Sudeste, Sul e Nordeste há uma maior prevalência dos cânceres de próstata (INCA, 2020). Na região centro-oeste, onde foi encontrada alta prevalência da doença com um aumento, aproximado, de 5\% nos últimos dez anos (2010 a 2019) (Pinheiro et al., 2021).

Os fatores de risco relacionados a incidência do CP são, idade (média de 66 anos), etnia (mais comum em africanos e menos comum em asiáticos) e história familiar positiva entre parentes de primeiro grau (o risco aumenta de duas a três vezes e quanto mais pessoas afetadas, maior o risco). Em menor proporção, a dieta e estilo de vida, como tabagismo e sedentarismo também estão relacionados a essa condição. O CP hereditário $(\mathrm{CPH})$ é definido como famílias que se enquadram nos critérios 
Johns Hopkins, com três ou mais parentes de primeiro grau diagnosticados com CP, três gerações sucessivas com a doença, ou pelo menos dois parentes com diagnóstico de CP de início precoce (antes dos 56 anos) (Brandão, Paulo \& Teixeira, 2020).

\subsection{Sinais e sintomas}

O CP não é uma doença clinicamente alarmante, mas sim silenciosa e progressiva. Os estágios iniciais não apresentam sintomas, normalmente começam a aparecer apenas quando a doença já está mais avançada, comuns tanto ao câncer como à hiperplasia prostática benigna. Entre os sintomas, destaca-se a polaciúria (aumento da frequência urinária durante o dia), noctúria (aumento da frequência urinária durante à noite), disúria (dor, desconforto ou queimação ao urinar), jato urinário fraco, disorgasmia (dificuldade para alcançar o orgasmo), gotejamento terminal, esvaziamento incompleto, micção em dois tempos, hematúria (presença de sangue na urina) e espermatúria (presença de esperma ou espermatozoide na urina) (Sarris et al., 2018; Mota \& Barros, 2019; Brasileiro, 2019).

Ademais, o CP gera um impacto sobre a sexualidade com sintomas como: disfunção erétil, perda de massa muscular, perda de libido, fadiga e feminização do corpo (Coutinho, 2018; Costa, 2018; Oliveira, 2018). Com isso, percebe-se que o aspecto emocional masculino é afetado, causando sentimentos como, desânimo, distanciamento, baixa autoestima, isolamento social e à dificuldade de aceitação da doença. O impacto social e cultural é muito forte e atinge muitos homens devido os ideais de masculinidade propostos pela sociedade (Coutinho, 2018; Costa, 2018; Oliveira, 2018).

A depressão é uma das principais repercussões psicológicas que interferem na qualidade de vida dos homens acometidos pelo $\mathrm{CP}$, pois, além da repercussão clínica, o paciente convive diariamente com a dor física e risco de morte relativos à ocorrência de possíveis metástases e recorrência da doença. Além disso, o medo da impotência sexual, angústia da perda de controle urinário, incapacidade de ter ereções satisfatórias e insegurança de ser abandonado pela parceira/o sexual; são alguns sentimentos expressos pelos pacientes com $\mathrm{CP}$, afetando a qualidade de vida no que diz respeito à saúde física e emocional desses homens (Seemann et al., 2018).

\subsection{Evidências terapêuticas}

$\mathrm{O}$ tratamento do $\mathrm{CP}$ é individualizado, considerando o tamanho do tumor, expectativa de vida do paciente, suas comorbidades, infiltração, histologia da neoplasia, e os possíveis efeitos colaterais do tratamento. Os tipos terapêuticos mais utilizados são prostatectomia radical (PR), radioterapia (RT) externa, braquiterapia (BT) e vigilância ativa (VA) (Arias et al., 2015; Morbeck et al., 2019).

Doentes em estágio inicial de riscos baixo e intermediário, com doença localizada na próstata, as opções terapêuticas são PR, RT com ou sem hormonioterapia (HT) ou VA. A VA é de maior prevalência para os pacientes com câncer de baixo risco, aqueles com expectativa de vida inferior a 20 anos, para tumores de risco intermediário favorável e aqueles com expectativa de vida inferior a 10 anos em casos específicos. Já, pacientes com expectativa de vida superior a cinco anos e que não tenham contraindicação cirúrgica, o procedimento mais adequado é a PR (Morbeck et al., 2019).

A PR envolve a retirada da próstata e das vesículas seminais, com ou sem esvaziamento das cadeias linfonodais pélvicas. Indicada em pacientes com risco intermediário com expectativa de vida maior que 10 anos. A BT é feita no CP de baixo risco com expectativa de vida menor de 10 anos, utiliza o implante permanente de sementes radioativas (baixa taxa de dose) ou por cateteres como fonte de irídio (alta taxa de dose). Pacientes cujo estadiamento sugere doença avançada localmente, com metástases para órgãos vizinhos, são classificados como de alto risco para progressão ou recorrência e as opções de tratamento são RT associada à HT de longa duração e PR associada à linfadenectomia pélvica estendida (Morbeck et al., 2019; Morbeck et al., 2019). 
Além de apresentar os aspectos gerais do $\mathrm{CP}$, a presente revisão visa descrever os aspectos e alterações moleculares necessárias para o desenvolvimento do câncer de próstata primário. Contribuir em um aspecto científico, principalmente junto aos profissionais da área da saúde com o propósito de melhorar o processo de diagnóstico precoce e, consequentemente, o tratamento específico, abordando as vias moleculares afetadas por esta condição. O resultado desse processo é de suma importância para os pacientes oncóticos, visto que proporcionará melhor qualidade, longevidade e expectativa de vida para os mesmos.

\section{Metodologia}

Este trabalho se tratou de uma revisão de literatura abordando as principais alterações moleculares no desenvolvimento do câncer de próstata. Foi realizada uma busca nos bancos de dados (PUBMED), Scientific Electronic Library Online (SCIELO), Instituto Nacional de Câncer (INCA), Science Direct e Google Acadêmico. Foram utilizadas como descritores as palavras "câncer de próstata", "alterações moleculares", "neoplasias", e seus respectivos equivalentes na língua inglesa. Foram também utilizados os capítulos das literaturas Bogliolo Patologia Geral 9a edição "Distúrbios da proliferação e da diferenciação celulares" e Robbins Patologia Básica $10^{\mathrm{a}}$ edição "Neoplasias".

A partir dos descritores supracitados, o critério de inclusão foi a utilização de artigos compreendidos entre 2015 à 2021, disponíveis em português, inglês e espanhol. Foram excluídos artigos que não relacionavam o câncer de próstata com as alterações moleculares ou com dados quantitativos desatualizados.

\section{Resultados e Discussão}

\subsection{Alterações moleculares no câncer de próstata primário}

O câncer de próstata primário $(\mathrm{CPa})$ é caracterizado por ser localizado especificamente na próstata, ou seja, não há disseminação através de metástases para órgãos e tecidos vizinhos. Geralmente assintomático, diagnosticado com exames de acompanhamento nomeados como triagem por exame de toque retal (ETR) e antígeno prostático específico (PSA), realizados anualmente após os 45 anos (BVSMS, 2015).

\subsubsection{Genes ETS}

$\mathrm{O} \mathrm{CPa}$ é andrógeno dependente, este está associado à superexpressão de um grupo de genes pertencentes à família ETS (E-26 transformation-specific), sendo esse o principal aspecto molecular na patogênese. Os genes da família ETS codificam diferentes fatores de transcrição e atuam em situação de normalidade na regulação de funções celulares como proliferação, diferenciação, angiogênese e apoptose. No processo de carcinogênese eles são geralmente, superexpressos e a alteração acontece no início da progressão maligna, porém, não estão associadas ao desfecho clínico. A superexpressão de ETS pode ser mediada por mecanismos epigenéticos ou translocações crípticas de todo o lócus do gene para uma vizinhança transcricionalmente ativa (Marshall et al., 2019; Rodrigues et al., 2015).

Os subtipos de CPa mais frequentes apresentam fusões dos genes da família ETS que ocorrem em $50 \%$ dos casos e mutações principalmente nos genes ERG, SPOP, CHD1 e BRCA1 e/ou BRCA2 (The Cancer Genome Atlas Research Network, 2015). Desses, de $8-12 \%$ dos genes envolvidos na via de reparo do DNA apresentam mutações deletérias no CP (Marshall et al., 2019; Rodrigues et al., 2015). 


\subsubsection{Superexpressão de $E R G$}

ERG (ETS-related gene) é um proto-oncogene, membro da família ETS, o qual codifica a proteína ERG, que funciona como um regulador transcricional. Porém, quando a proteína é superexpressa ou fundida com outros genes, pode se transformar em um oncogene. Por exemplo, o gene TMPRSS2 (transmembrane protease, serine 2) e o gene ERG, ambos localizados no cromossomo 21, sofrem rearranjos cromossômicos e se fundem, formando assim, TMPRSS2:ETS. Esse processo ocorre em 50\% dos CP e está presente durante a transição de lesões de neoplasia intraepitelial prostática (PIN - prostatic intraepithelial neoplasia) de alto grau para carcinoma invasivo (Feng, Brenner, Hussain \& Chinnaiyan, 2015; The Cancer Genome Atlas Research Network, 2015; Sandoval el al., 2019).

O ERG não é expresso no tecido normal da próstata. Dessa forma, quando expresso nesse tecido, acelera a carcinogênese, principalmente após a perda da proteína supressora de tumor PTEN (Phosphatase and Tensin Homolog) ou no contexto de superexpressão do receptor de andrógeno nas células desse tecido (Feng, Brenner, Hussain \& Chinnaiyan, 2015).

\subsubsection{PTEN e P-53}

O PTEN (Phosphatase and Tensin Homolog) é um gene supressor de tumor que, em situação de homeostase, regula negativamente a via PI3K/AKT (sendo AKT um conjunto de três proteínas quinases serina/treonina específicas a qual, na sua forma ativa, proporciona um controle no crescimento e proliferação celular e proporciona a proteção de células contra a apoptose), estimulando, assim, a apoptose e bloqueando a proliferação e o crescimento celular. A ausência de PTEN leva à ativação da via de sinalização PI3K/AKT e tumorigênese. Ademais, a PTEN pode interagir e regular diretamente a estabilidade da P-53 (uma fosfoproteína nuclear com função de controle do ciclo celular, reparo do DNA e indução da apoptose sendo, portanto, um importante supressor de tumor), interferindo, assim, na atividade transcricional de uma maneira independente de AKT. Dessa forma, a perda de PTEN também pode levar à ativação na via de sinalização c-Jun $\mathrm{NH}_{2}$-quinase terminal (JNK proteína que atua na regulação do processo de morte celular) independente da via de sinalização PI3K/AKT. Portanto, a falta de PTEN modifica várias vias de sinalização que podem desencadear ou acelerar o desenvolvimento do CPa (Sun, Li, Wang, Fan,\& Wangautor, 2019).

\subsubsection{BRCA1 e BRCA2}

Os genes supressores de tumor BRCA1 (Breast cancer1) e BRCA2 (Breast cancer2) são responsáveis pela síntese proteica de BRCA1 e BRCA2, respectivamente. Possuem a função de suprimir o desenvolvimento de tumores através da ativação de mecanismos de reparação das moléculas de DNA danificadas. As mutações desses genes em mulheres estão associadas ao câncer de mama e ovário e no homem ao CP (Junejo \& AlKhateeb, 2020).

Pacientes que apresentem mutações nesses genes, apresentam a possibilidade de um CP mais agressivo, com taxas mais altas de recorrência e mortalidade, início mais comum em jovens, alta taxa de afecção de linfonodos e metástase à distância. As mutações germinativas heterozigóticas no gene $B R C A 2$ podem ter efeitos deletérios nos alelos funcionantes, devido a efeitos secundários nocivos, desencadeados por medicamentos alquilantes, radioterapia ionizante, espécies reativas de oxigênio (EROs) e químicos mutagênicos (Junejo \& AlKhateeb, 2020).

O CPa localizado evolui com mais facilidade para câncer de próstata metastático resistente à castração (CPMRC), com taxas de sobrevida de 5 anos em 50-60\% dos pacientes quando presente a mutação no BRCA2. O gene BRCA2 é mais encontrado em CPa de início precoce, com idade inferior a 65 anos. A incidência de mutações BRCAl e BRCA2 em pacientes com CPa, em comparação com o CPMRC, é extremamente baixa (Marshall et al., 2019; Taylor et al., 2017; Brandão et al., 2020; Petrovics et al., 2019). 


\subsubsection{CHD1 e MAP3K7}

O CHD1 (Chromodomain Helicase DNA Binding Protein 1) é um fator de remodelação de cromatina, envolvido na regulação da transcrição gênica, através da interação com a cromatina e manutenção da pluripotência celular em células tronco. Já o gene MAP3K7, codifica à proteína MAP3K7 (mitogen-activated kinase quinasse kinase 7), uma enzima alvo de múltiplas moléculas sinalizadoras, tais como TGF $\beta, \mathrm{TNF} \alpha$, IL-1, etc. Recentes trabalhos demonstram que a supressão dupla de MAP3K7 e CHDl promove uma agressiva tumorigênese em cobaias, porém a co-deleção de ambos os genes pode não ser o principal responsável de metástase, porém são mediadores críticos da progressão para um carcinoma invasivo. Câncer com ausência de CHD1 pode se associar a um fenótipo menos agressivo (He et al., 2019; Rodrigues et al., 2016).

Por outro lado, alterações em $C H D 1$, podem diminuir as junções intercelulares, facilitando a metástase em outros tipos de câncer. Já no $\mathrm{CPa}$, a alteração molecular recorrente é a da superexpressão de $C H D 1$, considerando que a adesão intercelular entre as células tumorais e as células normais está aumentada no estágio tardio de formação do tumor. Além disso, o polimorfismo de CHD1 também eleva o risco de CPa. (He et al., 2019; Rodrigues et al., 2016).

\subsubsection{SPOP}

O SPOP é um gene que codifica a proteína SPOP (Speckle type POZ protein) a qual tem função no controle da estabilidade da proteína do receptor de andrógeno e de alguns de seus coativadores transcricionais. Especificamente no $\mathrm{CP}$, as mutações afetam mais o domínio MATH (definido pela homologia entre os domínios TRAF-C das proteínas intracelulares TRAF [fatores associados aos receptores do fator de necrose tumoral (TNF), ou TRAFs, regulam a sinalização do crescimento celular e a apoptose através da interação com receptores ligados à membrana por meio dos seus domínios TRAF-C] e uma região terminal das metalloendopeptidases extracelulares específicas meprins A e B, [implicadas em processos de desenvolvimento, normais e patológicos através da hidrolisação de uma variedade de peptídeos e proteínas], portanto, MATH é um domínio associado a interações entre essas duas proteínas aparentemente não relacionadas funcionalmente) da proteína SPOP, ocorrendo assim, a desregulação de vias moleculares que afetam a transcrição gerando instabilidade do genoma. Mutações no gene SPOP causam um aumento da sinalização do receptor de andrógeno (RA) (Boysen et al., 2019).

A deleção de CHD1 em conjunto com as mutações em SPOP são prevalentes no CPa e provocam um aumento da atividade transcricional de RA, ausência de rearranjos $E R G$ e padrão epigenético específico. Mutações em SPOP possuem menor incidência em CP metastático (Boysen et al., 2019; The Cancer Genome Atlas Research Network, 2015; He et al., 2019).

\section{Considerações Finais}

Para investigar a evolução molecular e clínica do paciente com CP necessita-se de uma análise abrangente e integrativa das primeiras alterações moleculares e mecanismos mutacionais. Em vista desse fator, o CP é uma doença altamente heterogênea sendo causado por eventos frequentes, como fusões reguladas por andrógenos de $E R G$ e outros membros da família ETS, ou mutações recorrentes de SPOP e, em outros casos, por aberrações genômicas menos comuns (Gerhauser et al., 2018; The Cancer Genome Atlas Research Network, 2015). Concomitantemente, mutações ou expressão gênica anormal associada a genes clássicos como P-53, PTEN, BRCA1 e BRCA2 podem contribuir para o desenvolvimento de CPa. Estudos epidemiológicos também indicaram que os portadores de BRCAl e BRCA2 têm o maior risco de desenvolver CPa em comparação com os não portadores dessas mutações, estando associado com subtipos mais agressivos e com baixas taxas de sobrevivência (Kgatle et al., 2016).

Embora o amplo espectro de modificações em tumores com fusões ETS tenha sido previamente caracterizado, observase diferenças adicionais entre os perfis epigenéticos desses tumores. Tumores de fusão positiva $E R G$ podem ser subdivididos em dois subtipos de metilação, um com níveis mais baixos de metilação e outro com um espectro distinto de hipermetilação. O que 
impulsiona esses grupos epigeneticamente distintos de tumores positivos para a fusão ETS é desconhecido, mas há uma diversidade considerável em seus perfis de metilação de DNA (The Cancer Genome Atlas Research Network, 2015).

Assim, as alterações genéticas e epigenéticas combinadas são reconhecidamente, eventos promotores do câncer. Como discutido acima, o envelhecimento, meio ambiente e histórico familiar são os três principais fatores de risco do CPa. Todos esses três, estão ligados a alterações epigenéticas nos genomas que podem levar a mudanças globais nos padrões de expressão gênica que geralmente são pró-tumorais. Diversas alterações epigenéticas, são progressivamente acumuladas durante o envelhecimento e contribuem diretamente para a transformação celular (Chinaranagari et al., 2018), porém, alterações epigenéticas específicas fogem do escopo deste trabalho.

Conclui-se, portanto, que mais estudos sejam necessários para determinar quais eventos estão relacionados à patogênese do CP, as descobertas apresentadas mostram a grande variabilidade de alterações que ocorrem na formação desse câncer. Clinicamente a evidência de mutações em genes tumorais e supressores de tumor pode ser utilizada para selecionar estratégias de tratamento individualizados, mais eficazes e com menos efeitos colaterais ao paciente. Além disso, a detecção de alterações na evolução do CP, otimizam o diagnóstico e proporcionam o descobrimento precoce da doença, consequentemente uma grande possibilidade de cura do paciente. Logo, para a melhor compreensão deste quadro, sugere-se a realização de trabalhos com maior espectro amostral, com a elaboração de pesquisas, investigações específicas e aperfeiçoadas sobre as possíveis alterações moleculares no desenvolvimento do câncer de próstata, seja ele primário ou os demais, será possível promover uma melhor qualidade, longevidade e expectativa de vida para os homens afetados por essa doença.

\section{Referências}

Arias, E., Astudillo, P., \& Manterola. C. (2015). Segunda neoplasia após tratamento para câncer de próstata localizado Segunda neoplasia após tratamento de câncerde próstata localizado. Actas Urológicas Españolas, 36(10), 583-589. https://doi.org/10.1016/j.acuro.2011.10.012.

Biblioteca Virtual em Saúde do Ministério da Saúde (BVSMS). (2015). Câncer de próstata. https://bvsms.saude.gov.br/bvs/dicas/137cancer_prostata.html.

Boysen, G. et al. (2019). SPOP-Mutated/CHD1-Deleted Lethal Prostate Cancer and Abiraterone Sensitivity. Clin Cancer Res, 24(22) 5585-5593. 10.1158/10780432.CCR-18-0937.

Brandão, A., Paulo, P., \& Teixeira, M. R. (2020). Hereditary Predisposition to Prostate Cancer: From Genetics to Clinical Implications. Int J Mol Sci, 21(14), 124. 10.3390/ijms21145036.

Brasileiro-filho, G. (2019). Bogliolo Patologia Geral. (9a ed.). Guanabara Koogan.

Chinaranagari, A., Sharma, P., Bowen, N. J., \& Chaudhary, J. (2018). Prostate Cancer Epigenome. Methods Mol Biol, 125-140. 10.1007/978-1-4939-1804-1_7.

Coutinho, M. P. L., Costa, J. A., \& Oliveira, A. R. (2018). A relação entre masculinidade e câncer de próstata: uma revisão sistemática. Revista Principia. (43), 11-22.

Feng, F. Y., Brenner, C. J., Hussain, M., \& Chinnaiyan, A. M. (2015). Molecular Pathways: Targeting ETS Gene Fusions in Cancer. Clin Cancer Res, 20(17), 4442-4448. 10.1158/1078-0432.CCR-13-0275.

Gerhauser, C. et al. (2020). Molecular evolution of early onset prostate cancer identifies molecular risk markers and clinical trajectories. Cancer Cell, 34(6), 996-1011. 10.1016/j.ccell.2018.10.016.

Gyorgy Petrovics, G. et al. (2019). Increased frequency of germline BRCA2 mutations associates with prostate cancer metastasis in a racially diverse patient population. Prostate Cancer Prostatic Dis, 22(3), 406-410. 10.1038/s41391-018-0114-1.

He, Z., Duan, X., \& Zeng, G. (2019). Identification of potential biomarkers and pivotal biological pathways for prostate cancer using bioinformatics analysis methods. PeerJ, 1-21. 10.7717/peerj.7872.

Instituto Nacional De Câncer - INCA. Como surge o câncer? < https://www.inca.gov.br/como-surge-o-cancer>

Instituto Nacional De Câncer - INCA. Estimativa 2020. <https://www.inca.gov.br/estimativa/introducao>

Instituto Nacional De Câncer - INCA. Introdução. 〈https://www.inca.gov.br/estimativa/introducao〉

Instituto Nacional De Câncer - INCA. O que é câncer? 〈https://www.inca.gov.br/o-que-e-cancer〉

Instituto Nacional De Câncer - INCA. Síntese de Resultados e Comentários. < https://www.inca.gov.br/estimativa/sintese-de-resultados-ecomentarios\#: :text=A\%20estimativa\%20mundial\%20aponta\%20o,33\%2C1\%2F100\%20mil. > 
Research, Society and Development, v. 10, n. 16, e539101623969, 2021

(CC BY 4.0) | ISSN 2525-3409 | DOI: http://dx.doi.org/10.33448/rsd-v10i16.23969

Junejo, N. N., \& AlKhateeb, S. S. (2020). BRCA2 gene mutation and prostate cancer risk. Saudi Med J, 41(1), 9-17. 10.15537/smj.2020.1.24759.

Kgatle, M. M., Kalla,A. A., Islam, M. M., Sathekge, M., \& Moorad, R. (2016). Prostate Cancer: Epigenetic Alterations, Risk Factors, and Therapy. Prostate Cancer. 1-11. 10.1155/2016/5653862.

Marshall, C. H., Fu, W., Wang, H., Baras,A. S., Lotan, TM L., \& Antonarakis, E. S. (2019). Prevalence of DNA repair gene mutations in localized prostate cancer according to clinical and pathologic features: Association of Gleason score and tumor stage. Prostate Cancer Prostatic Dis, 22(1), 59-65. 10.1038/s41391018-0086-1.

Morbeck,I. A. P., Gadia,R., Chaves, N. R., \& Santos,M. (2019). Câncer de próstata. Diretrizes Oncológicas. 1-24. https://diretrizesoncologicas.com.br/wpcontent/uploads/2019/10/Diretrizes-oncologicas_separata_Prostata.pdf.

Morbeck,I. A. P., Gadia,R., Chaves, N. R., Degrande, F. A. M., \& Leite, E. T. T. (2019). Câncer de próstata. Diretrizes Oncológicas. 385-404. https://diretrizesoncologicas.com.br/wpcontent/uploads/2019/01/Diretrizes-oncolo\%CC\%81gicas-2_Parte27.pdf.

Mota, T. R., \& Barros, D. P. O. (2019). Profile of prostate cancer patients in the reference hospital in the Pernambuco state. Rev. bras. anal. Clin. Recife, 50(4) 334-338. 10.21877/2448-3877.201900766

Pinheiro,E. S., Carneiro,P. H. G., Araújo,E. H.V., Oliveira,A. S.O., Valadão,D. V.; Prado, S. C., \&Crispim,L.F. (2021). Diagnósticos de hiperplasia benigna e câncer de próstata em um município do sudoeste goiano: análise de 20 anos. Brazilian Journal of Development, 7(1), 3963-3974. 10.34117/bjdv7n1-268.

Rodrigues, L. U. et al. (2016). Coordinate loss of MAP3K7 and CHD1 promotes aggressive prostate câncer. Cancer Res, 75(6), 1021-1034. 10.1158/00085472.CAN-14-1596.

Sandoval, G. J. et al. (2018). Binding of TMPRSS2-ERG to BAF chromatin remodeling complexes mediates prostate oncogenesis. Mol Cell, 71(4), 554-566. 10.1016/j.molcel.2018.06.040.

Sarris, A. B., candido, F. J. L. F., Filho, C. R. P.; Staichak, R. L.; Torrani. A. C. K., \& Sobreiro, B. P. (2018). Câncer de próstata: uma breve revisão atualizada. Repositório digital institucional UFPR, Curitiba, 19(1), 137-151.

Seemann, T., Pozzobom, F., Vieira, M. C. S., Boing, F., Machado, Z., \& Guimarães, A. C. A. (2018). Influence of symptoms of depression on the quality of life of mendiagnosed with prostate cancer. Rev. bras. geriatr. gerontol. 21(1), 70-78.

Sun, J., Li, S., Wang, F., Fan, C., \& Wangautor, J. (2019). Identification of key pathways and genes in PTEN mutation prostate cancer by bioinformatics analysis BMC Med Genet, (20), 1-9. 10.1186/s12881-019-0923-7.

Taylor, R. A. et al. (2017). Germline BRCA2 mutations drive prostate cancers with distinct evolutionary trajectories. Nat Commun. $10.1038 /$ ncomms13671.

The Cancer Genome Atlas Research Network. (2015). The Molecular Taxonomy of Primary Prostate Cancer. Cell, 163(4), 1011-1025. https://doi.org/10.1016/j.cell.2015.10.025. 